\title{
Deactivation of ultrashallow boron implants in preamorphized silicon after nonmelt laser annealing with multiple scans
}

\author{
J. A. Sharp, ${ }^{\text {a),b) }}$ N. E. B. Cowern, R. P. Webb, ${ }^{\text {b) }}$ and K. J. Kirkby ${ }^{\text {b) }}$ \\ Advanced Technology Institute, School of Electronics and Physical Sciences, University of Surrey, \\ Guildford GU2 7XH, United Kingdom \\ D. Giubertoni, S. Gennaro, and M. Bersani \\ ITC-irst Centro per la Ricerca Scientifica e Tecnologica, Povo (Trento) 38050, Italy \\ M. A. Foad \\ Applied Implant Technologies, Applied Materials Inc., 974 E. Arques Avenue, Sunnyvale, \\ California 94086 \\ F. Cristiano \\ LAAS/CNRS, 7 Av. Du Col. Roche, 31077 Toulouse, France \\ P. F. Fazzini \\ CEMES-CNRS, 29 Rue Jeanne Marvig, 31055 Toulouse, France
}

(Received 2 August 2006; accepted 22 September 2006; published online 6 November 2006)

\begin{abstract}
Electrical activation and redistribution of $500 \mathrm{eV}$ boron implants in preamorphized silicon after nonmelt laser annealing at $1150{ }^{\circ} \mathrm{C}$ and isochronal rapid thermal postannealing are reported. Under the thermal conditions used for a nonmelt laser at $1150{ }^{\circ} \mathrm{C}$, a substantial residue of end-of-range defects remained after one laser scan but these were mainly dissolved within ten scans. The authors find dramatic boron deactivation and transient enhanced diffusion after postannealing the one-scan samples, but very little in the five- and ten-scan samples. The results show that end-of-range defect removal during nonmelt laser annealing is an achievable method for the stabilization of highly activated boron profiles in preamorphized silicon. (C) 2006 American Institute of Physics. [DOI: $10.1063 / 1.2385215]$
\end{abstract}

The continued downscaling of complementary metaloxide-semiconductor devices requires ultrashallow and abrupt source/drain extension regions with a low sheet resistance. ${ }^{1}$ Among the other processes nonmelt laser annealing has gained attention as a means of achieving these requirements by its short process time and high annealing temperature, and hence low thermal budget, resulting in high dopant solubility. ${ }^{2-5}$ A problem exists with creating highly active profiles when boron is implanted in conjunction with a preamorphizing germanium implant; deactivation occurs during postactivation thermal processes. ${ }^{6-12}$ This deactivation is thought to be driven by the release of silicon interstitials from end-of-range (EOR) defects that evolve through nonconservative Ostwald ripening during annealing. ${ }^{13}$ The interstitials flow towards the surface and decorate the boron profile, producing boron interstitial clusters. ${ }^{14-17}$ In this letter, multiple laser scan annealing at $1150{ }^{\circ} \mathrm{C}$ followed by isochronal rapid thermal postannealing at lower temperatures is used to investigate the role of end-of-range defects in the redistribution and deactivation of ultrashallow $\mathrm{B}$ profiles in preamorphized and nonmelt laser-annealed silicon.

$N$-type (100) Czochralski-silicon wafers were preamorphized with $5 \mathrm{keV} \mathrm{Ge}$ to a dose of $1 \times 10^{15} \mathrm{~cm}^{-2}$ producing a surface amorphous layer to a depth of $\sim 15 \mathrm{~nm}$. $500 \mathrm{eV} \mathrm{B}^{+}$ was implanted into the amorphous layer to a dose of 1 $\times 10^{15} \mathrm{~cm}^{-2}$. Both implants were made using an Applied Materials Quantum X implanter. The wafers were exposed to a scanning diode laser source operated under nonmelting

\footnotetext{
${ }^{a)}$ Electronic mail: j.sharp@surrey.ac.uk

${ }^{b)}$ Also at: Surrey Ion Beam Centre.
}

conditions, which was used to anneal three strips across the wafers, corresponding to one, five, or ten scans at a temperature of $1150{ }^{\circ} \mathrm{C}$. By using multiple laser scans to anneal the wafer, it allows a study of defect evolution as a function of increasing the thermal budget. The amorphous layer regrew by solid phase epitaxial regrowth during the annealing. Samples were taken from these strips and annealed in dry $\mathrm{N}_{2}$ for $60 \mathrm{~s}$ at temperatures ranging from 700 to $1000{ }^{\circ} \mathrm{C}$ using a Process Products Corporation rapid thermal annealing system operating with a $50{ }^{\circ} \mathrm{C} / \mathrm{s}$ heating ramp rate. The van der Pauw technique was used to measure the sheet resistance of the samples after laser and deactivation annealing. In addition, differential Hall measurements, which uses layer removal, and Hall measurements were employed to determine the peak active boron concentration of selected profiles. ${ }^{18}$ Secondary ion mass spectrometry (SIMS) was also carried out on selected samples using a Cameca Wf SC-ULTRA tool running a $500 \mathrm{eV} \mathrm{O} \mathrm{O}_{2}^{+}$primary beam $\left(68^{\circ}\right.$ angle of incidence with respect to the surface normal) with oxygen leak. The sample was loaded on a rotating stage in order to prevent the formation of ripples on the crater bottom. ${ }^{19}$ Defect images were taken in weak beam dark field conditions using conventional imaging conditions, i.e., $B=[001]$ zone axis with $g$ $=\langle 422\rangle$ diffracting vector and also the $B=[113]$ zone axis with a high index diffracting vector $(g=\langle 422\rangle)$ in order to increase defect contrast (visibility improvement) and the number of visible defect variants (increased apparent density). ${ }^{20,21}$

The sheet resistance results for the $500 \mathrm{eV} \mathrm{B} \mathrm{B}^{+}$implant after laser and then deactivation annealing can be seen in Fig. 1. The results show an initially low sheet resistance 


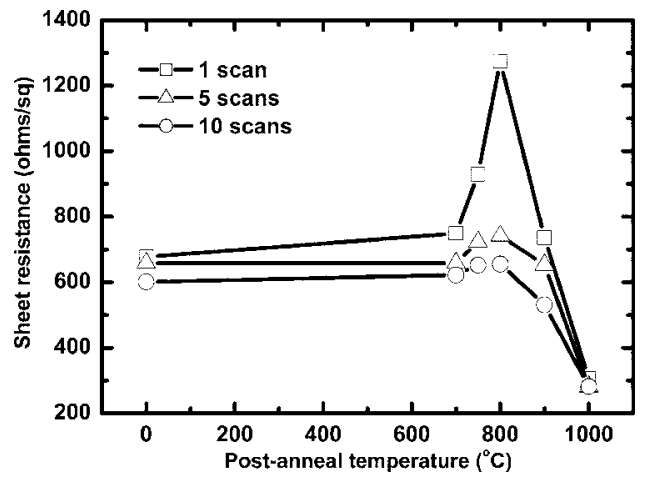

FIG. 1. Sheet resistance against postannealing temperature showing deactivation/reactivation of $500 \mathrm{eV} \mathrm{B}$ in preamorphized silicon after laser annealing at $1150{ }^{\circ} \mathrm{C}$ and isochronal postannealing for $60 \mathrm{~s}$. The $0{ }^{\circ} \mathrm{C}$ points correspond to activation by the laser only.

value, which increases as the postannealing temperature is increased (deactivation). Above $900{ }^{\circ} \mathrm{C}$ the sheet resistance drops considerably to values lower than those observed for laser annealing only. The samples that received only one scan show a much greater deactivation than the samples that received multiple laser scans. This trend is consistent with deactivation resulting from the dissolution of EOR defects. ${ }^{12,15,17}$ The lower amount of deactivation observed during the postannealing for the five- and ten-scan cases is similar to that observed by Lerch et al., ${ }^{22}$ who found that flash-lamp annealing with a peak temperature of $1275-1325{ }^{\circ} \mathrm{C}$ was sufficient to evolve the EOR defect band into dislocation loops. The supersaturation of interstitials at this stage of defect evolution is much lower than when $\{113\}$ defects are present, and hence the amount of deactivation during postannealing, driven by this supersaturation, is also reduced.

Figure 2(a) shows SIMS boron profiles of three samples that have been laser annealed with one, five, or ten scans. There is some degree of diffusion from the as-implanted profile during the laser annealing, which increases with the number of laser scans. A kink is observable in the one-scan sample at a concentration of $10^{19} \mathrm{~cm}^{-3}$. This kink develops into a boron peak at $16 \mathrm{~nm}$ that can be clearly seen after the sample has undergone postannealing at $700{ }^{\circ} \mathrm{C}$ for $60 \mathrm{~s}$ [Fig. 2(b)]. Since the amorphous layer is expected to be about $15 \mathrm{~nm}$ thick, this peak is a clear indication that B decoraes EOR defects that are presumably still present after a onelaser scan. Moreover, the redistribution to form this peak implies a significant amount of diffusion at concentrations below that of the original kink, which would only occur in the presence of a high interstitial supersaturation. In contrast, the five- and ten-laser-scanned samples do not show any substantial diffusion after the $700{ }^{\circ} \mathrm{C}$ postannealing, nor do they exhibit any other anomalous feature. The peak active boron concentrations for the ten-scan case are also shown (using a Hall scattering factor of 0.5 ). The peak active boron concentration starts at $\sim 4 \times 10^{20} \mathrm{~cm}^{-3}$ and drops only to $\sim 2$ $\times 10^{20} \mathrm{~cm}^{-3}$ after an $800{ }^{\circ} \mathrm{C}$ postannealing.

Further evidence for the presence of EOR defects after a one-laser scan at $1150{ }^{\circ} \mathrm{C}$ can be seen in Fig. 2(c), where the samples have been postannealed at $800^{\circ} \mathrm{C}$ for $60 \mathrm{~s}$. Here, transient enhanced diffusion is observed in the lowconcentration tail region of the profile. This effect is probably caused by a very high supersaturation of selfinterstitials, which could only be driven by the dissolution of Downloaded 30 Mar 2009 to 131.227 .178 .132 . Redistribution subje
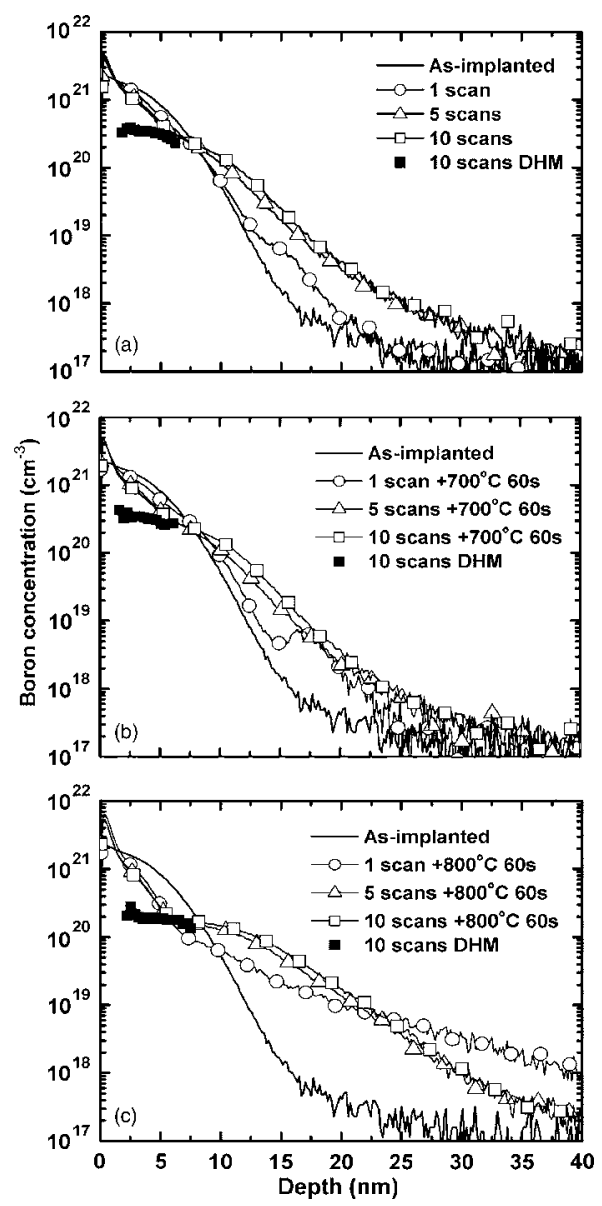

FIG. 2. SIMS profiles and differential Hall profiles (ten scan case) for $500 \mathrm{eV}$ B in Ge preamorphized silicon showing an as-implanted profile and (a) activated with one, five, or ten laser scans at $1150{ }^{\circ} \mathrm{C}$, (b) laser annealed at $1150{ }^{\circ} \mathrm{C}$ then postannealed at $700{ }^{\circ} \mathrm{C}$ for $60 \mathrm{~s}$, and (c) laser annealed at $1150{ }^{\circ} \mathrm{C}$ then postannealed at $800{ }^{\circ} \mathrm{C}$ for $60 \mathrm{~s}$.

EOR defects. An approximate estimate of the supersaturation can be obtained from the diffusion length in the tail region, which is of the order of $15 \mathrm{~nm}$. Based on standard B diffusivity values under equilibrium point-defect conditions, this implies a supersaturation $\sim 1000$, consistent with the presence of $\{113\}$ defects, which are known to form in the EOR band. No such enhancement is seen in the samples that received five or ten laser scans. In these samples, postannealing at $800{ }^{\circ} \mathrm{C}$ gives rise to diffusion with a much higher kink level of about $1.8 \times 10^{20} / \mathrm{cm}^{3}$, with a diffusion profile consistent with near-normal steady-state diffusion.

Transmission electron microscopy (TEM) analysis of the samples after the laser annealing steps reveals that a high density of EOR defects remain in the sample which received one laser scan [Fig. 3(a)] and that most of these are $\{113\}$ defects. Five-scan laser annealing is sufficient to evolve most of the EOR defects into dislocation loops [Fig. 3(b)] resulting in a lower supersaturation. This observation complements the sheet resistance trend, where the deactivation during postannealing is greatly reduced compared to that after just one scan. The TEM image for the ten-laser-scan case reveals a small number of residual dislocation loops [Fig. $3(c)]$. These defects are presumably more stable than those present after five scans (both ripening and dissolution of a defect population where the largest defects survive longest, will tend to produce this result), and their separation is very large (we see just a few defects in an area of the order of to AlP license or copyright; see http://apl.aip.org/apl/copyright.jsp 

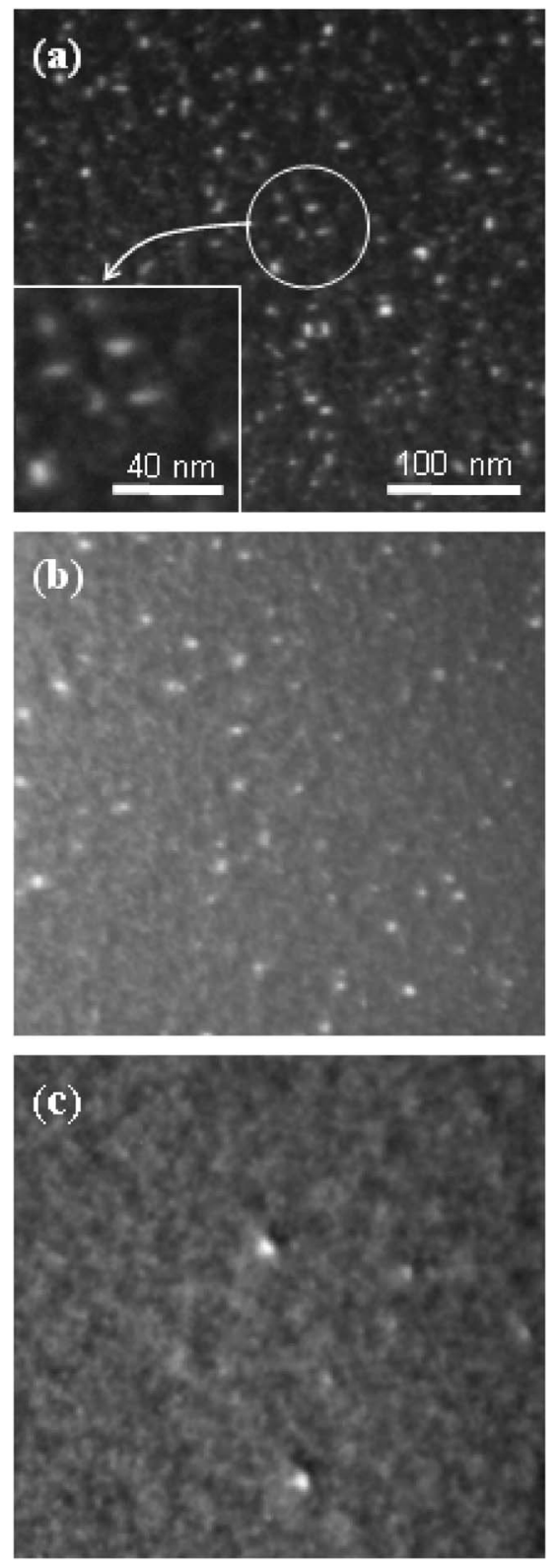

FIG. 3. Plan view WBDF TEM images in the $(g, 3 g)$ condition with $g$ $=[224]$ for $(\mathrm{a})-(\mathrm{c})$. (a) corresponds to a specimen which has received one laser scan, (b) corresponds that with five laser scans, and (c) corresponds that with ten laser scans.

$1 \mu \mathrm{m}^{2}$ ). Both of these factors may contribute to a reduction in mean supersaturation between the defects and thus to a further reduction in deactivation which we observe during the postannealing for this condition.

The presented results point consistently to the conclusion that for the single laser scan, there was not enough thermal budget to break up the EOR defects, leading to strong deactivation as a result of the release of interstitials during postannealing. By using five or ten laser scans at $1150{ }^{\circ} \mathrm{C}$, the EOR defects were largely removed, resulting in a greatly decreased deactivation and relaxation towards equilibrium diffusion behavior during postannealing.

In summary, we have studied nonmelt laser annealing as a tool for the formation of highly active ultrashallow boron profiles in preamorphized silicon. The deactivation of the boron after annealing using a nonmelt scanning laser with multiple scans was examined by studying the boron profiles after rapid thermal postannealing over a range of lower temperatures. Under conditions where a high density of $\{113\}$ defects are present after the laser annealing, subsequent lowtemperature processing leads to strong deactivation and transient enhanced diffusion, during which $\mathrm{B}$ also decorates these defects. In contrast, when the number of scans is sufficient to ripen the $\{113\}$ defects into loops, both deactivation and transient enhanced diffusion are strongly reduced during postannealing. Further reductions occur as the number of laser scans is increased-ripening and/or dissolving the loops even further.

The authors would like to acknowledge the U.K. Engineering and Physical Sciences Research Council (EPSRC) and the Surrey Ion Beam Centre for their support. One of the authors (J. A. S.) is supported by an EPSRC Doctoral Training Award. Another author (N.E.B.C.) holds a Research Chair supported by Applied Materials, Philips, and the U.K. Royal Academy of Engineering.

${ }^{1}$ International Technology Roadmap for Semiconductors, 2005, http:// public.itrs.net/

${ }^{2}$ S. Earles, M. Law, K. Jones, S. Talwar, and S. Corcoran, Mater. Res. Soc. Symp. Proc. 669, J4.1.1 (2001).

${ }^{3}$ S. Earles, M. Law, K. Jones, R. Brindos, and S. Talwar, Mater. Res. Soc. Symp. Proc. 610, B10.5.1 (2000).

${ }^{4}$ S. Earles, M. Law, R. Brindos, K. Jones, S. Talwar, and S. Corcoran, IEEE Trans. Electron Devices 49, 1118 (2002).

${ }^{5}$ S. Earles, M. Law, K. Jones, J. Frazer, S. Talwar, D. Downery, and E. Arevalo, Proceedings of the 12th IEEE International Conference on Advanced Thermal Processing of Semiconductors, 28-30 September 2004 (IEEE, Piscataway, NJ, 2004), p. 143.

${ }^{6}$ B. J. Pawlak, W. Vandervorst, A. J. Smith, N. E. B. Cowern, B. Colombeau, and X. Pages, Appl. Phys. Lett. 86, 101913 (2005).

${ }^{7}$ Y. Takamura, S. Jain, P. B. Griffin, and J. D. Plummer, Mater. Res. Soc. Symp. Proc. 669, J7.3.1 (2001).

${ }^{8}$ Y. Takamura, S. H. Jain, P. B. Griffin, and J. D. Plummer, J. Appl. Phys. 92, 230 (2002).

${ }^{9}$ Y. Takamura, P. B. Griffin, and J. D. Plummer, J. Appl. Phys. 92, 235 (2002).

${ }^{10}$ W.-E. Hong and J.-S. Ro, J. Appl. Phys. 97, 013530 (2005).

${ }^{11}$ R. Murto, K. Jones, M. Rendon, and S. Talwar, Proceedings of the 14th Ion Implantation Technology Conference (IEEE, Piscataway, NJ, 2000), p. 155 .

${ }^{12}$ B. J. Pawlak, R. Surdeanu, B. Colombeau, A. J. Smith, N. E. B. Cowern, R. Lindsay, W. Vandervorst, B. Brijs, O. Richard, and F. Crisitano, Appl. Phys. Lett. 84, 2055 (2004).

${ }^{13}$ C. Bonafos, D. Mathiot, and A. Claverie, J. Appl. Phys. 83, 3008 (1998).

${ }^{14}$ B. Colombeau, A. J. Smith, N. E. B. Cowern, W. Lerch, S. Paul, B. J. Pawlak, F. Cristiano, X. Hebras, C. Ortiz, and P. Pichler, Tech. Dig. - Int. Electron Devices Meet. 2004, 971.

${ }^{15}$ M. Aboy, L. Pelaz, L. A. Marqués, P. Lopez, J. Barbolla, V. C. Venezia, R. Duffy, and P. B. Griffin, Mater. Sci. Eng., B 114-115, 193 (2004).

${ }^{16}$ M. Aboy, L. Pelaz, L. A. Marqués, J. Barbolla, A. Mokhberi, Y. Takamura, P. B. Griffin, and J. D. Plummer, Appl. Phys. Lett. 83, 4166 (2003).

${ }^{17}$ F. Cristiano, N. Cherkashin, P. Calvo, Y. Lamrani, X. Hebras, A. Claverie, W. Lerch, and S. Paul, Mater. Sci. Eng., B 114-115, 174 (2004).

${ }^{18}$ T. Alzanki, R. Gwilliam, N. Emerson, and B. J. Sealy, Appl. Phys. Lett. 85, 1979 (2004).

${ }^{19}$ M. Bersani, D. Giubertoni, E. Iacob, M. Barozzi, S. Pederzoli, L. Vanzetti, and M. Anderle, Appl. Surf. Sci. 252, 7315 (2006).

${ }^{20}$ N. Cherkashin, P. Calvo, F. Cristiano, B. de Mauduit, and A. Claverie, Mater. Res. Soc. Symp. Proc. 810, 103 (2004).

${ }^{21}$ S. Boninelli, N. Cherkashin, A. Claverie, and F. Cristiano, Appl. Phys. Lett. (in press).

${ }^{22}$ W. Lerch, S. Paul, J. Niess, S. McCoy, T. Selinger, J. Gelpey, F. Cristiano, F. Severac, M. Gavelle, S. Boninelli, P. Pichler, and D. Bolze, Mater. Sci. Eng., B 124-125, 24 (2005). 